\title{
A Cross-Sectional Study of Bovine Babesiosis in Teltele District, Borena Zone, Southern Ethiopia
}

\author{
Alemu Hamsho', Gebregergs Tesfamarym¹, Gurara Megersa² and Mulisa Megersa ${ }^{1 *}$ \\ ${ }^{1}$ Jigjiga University, College of Veterinary Medicine, Jigjiga, Ethiopia \\ ${ }^{2}$ Yabello Regional Laboratory, Yabello, Ethiopia
}

\begin{abstract}
A cross-sectional study was conducted from November, 2013 to April, 2014 to assess the prevalence of bovine babesiosis in Teltele District, North West Borena Zone, Southern Ethiopia. A total of 384 blood samples were collected from ear vein of cattle from four peasant associations (PAs). In this study the overall prevalence of bovine babesiosis was found $16.9 \%$ (65/384) using microscopic examination of Geimsa stained blood smear. Significant variation was observed among study areas $(P<0.01)$. Four PAs were assessed and the lowest prevalence was recorded in Fulotole $(9.4 \%)$ followed by Hatuse $(13.6 \%)$, Kulcha $(18.2 \%)$ while the highest was recorded in Billa kebele $(27.85 \%)$. Higher prevalence was recorded in female $(17.5 \%)$ than male $(16.3 \%)$ with significant difference $(P<0.05)$. Age wise prevalence showed the highest prevalence among old animals $(23.5 \%)$ followed by adult $(15 \%)$ and young animals $(13.2 \%)$. Body condition of the animal was significantly associated $(P<0.001)$ and highest prevalence recorded in animals with poor body condition (35.96\%). Two species of Babesia identified were B. bovis $(9.9 \%)$ followed by $B$. bigemina $(7 \%)$. In conclusion the results of this study have indicated that bovine babesiosis was highly prevalent in the study area. This warrants appropriate tick control and strategic prophylactic treatment in order relive the current challenges in the focus area.
\end{abstract}

Keywords: Bovine babesiosis; Cross-sectional study; Teltele District

\section{Introduction}

Ethiopia with its great variation in climate and topology possesses the largest number of livestock in Africa and livestock production plays a major role in the development of Ethiopia's agriculture. The estimated livestock population in Ethiopia is 59 million cattle, 35 million sheep, 31 million goats, 2.3 million camels, 1.91 million horse, 6.75 million donkey, 0.35 million mule, 38 million poultry and 5,207,300 traditional, intermediate and modern beehive [1]. These livestock resource contribute $15 \%$ to gross domestic product (GDP) and $33 \%$ to agricultural output. Among the livestock, cattle directly provide food such as meat and milk, a non-food such as hide and indirectly to agricultural production by supplying essential inputs such as manure for replenishing soil fertility and restoring nutrients, animal traction and power for plowing and threshing, increasing the productivity of small holdings [2].

Despite the importance of livestock to the economy at large, the sub-sector has remained untapped. The little benefit from the enormous livestock resource of the country is attributable to a multitude of problems. This comprises of diseases, age-old, traditional management system, inferior genetic make-up coupled with under nutrition and complicated by malnutrition, harsh environment and absence of well-developed market infrastructure [3]. Livestock disease is among the major factors that affect the production and productivity having negative effects on the health of the livestock. The presence of diseases caused by haemoparasites is broadly related to the presence and distribution of their vectors. Arthropod transmitted haemoparasitic disease of cattle is caused by the trypanosome, babesia, theleria and anaplasma species [4].

Babesia species are intra erythrocytic protozoan parasites of domestic, wild and laboratory animals. It belongs to protozoan parasites of the genus Babesia, order Piroplasmida, phylum Apicomplexa and subclass Piroplamsia and are commonly referred to as 'piroplasmas' due to the pear-like shaped merozoites which live as small parasites inside RBC of mammals. They commonly infect cattle, sheep, goats, horses, pigs, dogs and cats and occasionally man. More than 100 known Babesia spp. have been identified which infect many types of mammalian host, out of these, 18 spp. cause disease in domestic animals. The organisms spread by arthropods like ticks and biting flies transplacentally and by blood transfusion. Almost any mammals, that serves as a host for a Babesia infected tick is a potential reservoir [5]. The principal species of Babesia that cause bovine babesiosis (BB) are: Babesia bovis, Babesia bigemina and Babesia divergens. Other Babesia that can infect cattle includes B. major, B. ovata, B. occultans and $B$. jakimovi [6].

Bovine babesiosis is the most important arthropod-borne disease of cattle worldwide that causes significant morbidity and mortality. It is the second most common blood-borne parasitic disease of mammals after the trypanosome and it was classified as list B disease according to OIE. The most prevalent species, B. bovis and B. bigemina, are found throughout most tropical and subtropical regions, particularly important in Asia, Africa, Central and South America, parts of southern Europe, and Australia. Although B. bovis is usually found in the same general geographic area as B. bigemina, slightly different groups of ticks spread these two species and some differences in their distribution can be seen. For example, $B$. bigemina is more widely distributed than $B$. bovis in Africa. The economic losses from these two organisms can be considerable, particularly in developing countries. Although babesiosis

*Corresponding author: Mulisa Megersa, Jigjiga University, College of Veterinary Medicine, Jigjiga, Ethiopia, Tel: +251-913110517; E-mail: mulisam38@gmail.com

Received April 01, 2015; Accepted April 23, 2015; Published April 25, 2015

Citation: Hamsho A, Tesfamarym G, Megersa G, Megersa M (2015) A CrossSectional Study of Bovine Babesiosis in Teltele District, Borena Zone, Southern Ethiopia. J Veterinar Sci Technol 6: 230. doi:10.4172/2157-7579.1000230

Copyright: (c) 2015 Hamsho A, et al. This is an open-access article distributed under the terms of the Creative Commons Attribution License, which permits unrestricted use, distribution, and reproduction in any medium, provided the original author and source are credited. 
can be controlled with vaccination and treated with antiparasitic drugs, the vaccines are live and have safety concerns and many effective drugs have been withdrawn from the market due to safety or residue problems [7].

Previous studies conducted on the distribution, abundance, and prevalence of haemoparasites species affecting livestock in different parts of Ethiopia have showed wide spread existence haemoparasites like anaplasmosis, babesiosis, cowdriosis, trypanosomosis and theileriosis (T. mutans) [8,9]. However, the detailed status of bovine babesiosis is not thoroughly studied in our country; particularly Teltele Woreda, Borena Zone, Southern Oromia Regional State and the information is so far scanty. Therefore, this study was done with the objectives to estimate prevalence and assess risk factors associated with bovine babesiosis in Teltele district.

\section{Materials and Methods}

\section{Description of study area and populations}

The study was carried out in four selected peasant associations (PAs) of Teltele district, located in North West Borena Zone, Oromia region, Southern Ethiopia from November, 2013 to April, 2014. The district is located at about $670 \mathrm{kms}$ from Addis Ababa and $100 \mathrm{kms}$ from Yabello town, the capital of Borena administrative zone and covers an estimated area of $10,990.33 \mathrm{~km}^{2}$. The area receives an annual rainfall about $250-650 \mathrm{~mm}$. The minimum and maximum daily temperature ranges from $22-37^{\circ} \mathrm{C}$. The area has an altitude of $710-1460$ masl. The agro ecological location of area is of "kola" type. A survey of the land in this woreda shows that $25 \%$ is arable (2.5\% was under cultivation), $48 \%$ pasture, $5 \%$ forest, $20 \%$ shrub and brush and the remaining $2 \%$ is considered swampy, degraded or otherwise unusable. The main important crops cultivated on the area include sorghum, corn, teff, haricot beans, chickpeas, wheat and barley.

Lake Chew Bahir is a notable local landmark. The area is located $4^{\circ} 50^{\prime} \mathrm{N}$ latitudinal and $37^{\circ} 25^{\prime} \mathrm{E}$ longitudinal. The district is bordered on the South West by Kenya, on the West and North by the Sagan River, which separates it from the Konso Woreda of SNNPR, on the North East by Yabello and on the South East by Dire. The district has 23 PAs. These PAs have a total livestock population of 668,898 constituting cattle 237,559, sheep 115,283, goat 207,057, donkey 11,343, mule 101, camel 1,612 and poultry 95,943. The four selected PAs are Fulotole, Hatuse, Kulcha and Billa which have total cattle population of 5,683, $2,398,10,024$ and 2,859 respectively according to the data collected by the Office of Teltele Pastoral Area Development Commission since 2014. The study populations were local Borena cattle managed under extensive management system. The study animals comprised of different age groups and both sexes.

\section{Study design and sampling methodology}

A cross-sectional study design was conducted from November 2013 to April 2014 in Borena cattle of Teltele district, Borena zone, Oromia region, southern Ethiopia. Information regarding age, sex, origin and body condition of the animals were recorded during sample collection. The ages of the animals was determined based on owners' information and as described by Delahunta and Habel [10]. Animals were conveniently classified as young ( $<3$ years), adult ( $4-6$ years) and old ( $>7$ years) age categories. Body condition score of animals were evaluated according to Nicholson and Butterworth [11] during sample collection and classified as good, medium and poor. Furthermore, previous history of treatment with any babecidal drugs was also recorded. Multi stage sampling technique was applied to select study area and peasant associations (PAs) and animals were proportionally sampled from each study areas.

\section{Sample size determination}

Sample size was calculated according to the formula given by Thrusfield [12] ( $\mathrm{n}=/ 1.96$ (Pexp (1-Pexp))/ $\mathrm{d}^{2}$ using 95\% level of confidence; expected prevalence (Pexp) of 50\% with desired absolute precision (d) of 5\%. Accordingly a total of 384 samples were taken from four PAs of which 96 animals from Fulotole, 88 from Hatuse, 121 from Kulcha and 79 from Billa.

\section{Sample collection and transportation}

Blood sampling was done after proper restraining of the animal according to Urquhart et al. [13]. Before blood collection, the area of puncture was cleaned, hair removed and disinfected with $70 \%$ alcohol. Then smaller marginal ear veins were punctured with sterile lancet and the first drops of blood were taken for thin smear preparation. Thin smears were prepared by applying the slide with blood on to a clean slide at an angle of $45^{\circ}$ and then gently moving forward. The slide was air dried and fixed for 2 minutes in methyl alcohol (absolute methanol). Soon after the slides were fixed and air dried it was put into slide box and transported to Yabello Regional Veterinary Parasitology Laboratory for examination of parasites.

\section{Laboratory investigation procedures}

Giemsa staining procedures and microscopic examination of slides was conducted according to OIE [14]. The slides were immersed in Giemsa stain (1:10 solution) in staining rack for 30 minutes. Then the slides were washed with distilled water to remove excess stain and made air dry. The stained blood smears were examined under oil immersion lens of microscope (100X) for appreciation and identification of different Babesia species according to their morphological characteristics [15].

\section{Data analysis}

The data collected during the study period were stored in Microsoft Excel spread sheet and analyzed by the statistical software called STATA version 11.0 for Windows (Stata Corp. College Station, USA). The prevalence was calculated by dividing the number of cattle found to be positive for Babesia by the total number of cattle examined for Babesia spp. The association of risk factors like age, sex, body condition and history of treatment with positivity for babesiosis was assessed using Chi-square test. In all the analyses, confidence interval (CI) was held at $95 \%$ and $P<0.05$ was set for statistical significance.

\section{Results}

From a total of 384 cattle examined, the overall prevalence was found $16.9 \%$ with $95 \%$ CI of $13.2-20.7$. The lowest prevalence $(9.4 \%)$ was recorded in Fulotole while the highest (27.9\%) was recorded in Billa kebele (PAs) as indicated (Table 1). Highest infection rates was observed in old cattle (23.5\%) followed by adults (15\%) and young (13.2\%). Body condition of the animals showed a significant association $(P<0.05)$ with positivity for babesiosis, while sex and age were not associated $(P>0.05)$ (Table 2). Two species of Babesia were identified with the prevalence of $(9.9 \%)(38 / 384)$ and $7 \%(27 / 384)$ for B. bovis and B. bigemina respectively (Table 3 ).

\section{Discussion}

In this study, the overall prevalence rate of bovine babesiosis was found to be $16.9 \%$ out of which two species of Babesia comprising of B. bovis (9.9\%) and B. bigemina (7\%) were identified using Giemsa 


\begin{tabular}{|c|c|c|c|c|}
\hline PAs & No. of tested & Positive & Prevalence (\%) & $X^{2}$ \\
\hline Fulotole & 96 & 9 & 9.38 & 13.64 \\
\hline Hatuse & 88 & 12 & 18.18 & \\
\hline Kulcha & 121 & 22 & 27.85 & \multirow{2}{*}{0.01} \\
\hline Billa & 79 & 22 & 16.93 \\
\hline
\end{tabular}

PAs=Peasant Associations No.=number

Table 1: Prevalence of babesiosis on the basis of PAs.

\begin{tabular}{|c|c|c|c|c|c|}
\hline Variable & No of tested & Positive & Prevalence & $x^{2}$ & $P$-value \\
\hline \multicolumn{6}{|l|}{ Sex } \\
\hline Male & 178 & 29 & 16.3 & \multirow{2}{*}{0.951} & \multirow{2}{*}{0.758} \\
\hline Female & 206 & 36 & 17.5 & & \\
\hline \multicolumn{6}{|l|}{ Age } \\
\hline Young & 129 & 17 & 13.2 & \multirow{3}{*}{3.8209} & \multirow{3}{*}{0.148} \\
\hline Adult & 140 & 21 & 15 & & \\
\hline Old & 115 & 27 & 23.5 & & \\
\hline \multicolumn{6}{|c|}{ Body condition } \\
\hline Good & 128 & 7 & 5.47 & \multirow{3}{*}{35.0860} & \multirow{3}{*}{0.000} \\
\hline Medium & 167 & 26 & 15.57 & & \\
\hline Poor & 89 & 32 & 35.96 & & \\
\hline \multicolumn{6}{|l|}{ Treatment } \\
\hline Treated & 92 & 10 & 10.87 & \multirow{2}{*}{3.1571} & \multirow{2}{*}{0.076} \\
\hline Untreated & 292 & 55 & 18.84 & & \\
\hline
\end{tabular}

Table 2: Prevalence of babesiosis on the basis of sex, age, body condition and treatment status in cattle.

\begin{tabular}{|c|c|c|c|}
\hline \multirow{2}{*}{ Total animals tested } & Babesia spp identified & Positive \\
\hline \multirow{3}{*}{384} & Babesia bovis & 38 & 9.9 \\
\cline { 2 - 4 } & Babesia bigemina & 27 & 7.03 \\
\cline { 2 - 4 } & Total & 65 & 16.93 \\
\hline
\end{tabular}

Table 3: Prevalence of babesiosis on the basis of Babesia species identified.

stained microscopic examination. This finding was higher than the previous findings 6.6\% from Malakand Agency [16] and Sargodha District, Pakistan [17], and 9.9\% from study conducted in Khyber Pakhtunkhwa, Pakistan [18]. However, this result was lower than the earlier reports from Malaysia (42\%) [19] and the prevalence of $26.6 \%$ from a cattle raised nearby forest in Salakpra Wildlife Sanctuary in Kanchanaburi province [20]. The discrepancy in the prevalence of bovine babesiosis might be due to different factors like managemental condition of the focus area use of acaricides during tick infestation, farming system and proper use of antiparasitic drugs, fluctuations of parasites during chronic course of the disease and in carriers animals, sensitivity of test used, distribution of infected vector and accessibility of animals to wildlife sanctuary and parks and forest area harboring the Babesia vectors $[5,21,22]$. Other cause of variation may be due to different geographical conditions and or due to different breeds of cattle studied [23].

The highest prevalence of bovine babesiosis was recorded in Billa peasant association (PA) (27.9\%) among the study areas considered for this study. The possible explanation for this might be associated with that Billa PA mainly contains Borena pastoralists who have wide ranging land and keep their cattle far away to areas having forests and bushes which is believed to be the most suitable for the vector of the Babesia but the three remaining kebeles (Fulotole, Hatuse and Kulcha) are mainly predominated by the Konso people who are mainly agropastoralist practicing both crop and livestock production. The latter study areas also practice keeping their cattle near to their cultivated land using agricultural by-product. This could reduce the probability of their cattle exposure to high tick infestation and accessibility to tick infested area. This finding concurs with the study conducted in Uganda that the prevalence of infection with tick-borne parasites varied with livestock production and/or grazing system being higher in open grazing system (39.1\%) compared to zero-grazing system (6.9\%) [24].

In the present study slightly higher infection rate was recorded in female $17.48 \%(36 / 206)$ as compared to male animals $16.29 \%(29 / 178)$. Even though this difference was not statistically significant, this finding was in agreement with the report of Kocan et al. [25] who found higher prevalence of babesiosis in female $11.2 \%(184 / 1639)$ compared to male cattle $6.96 \%$. Moreover, the higher prevalence of tick borne diseases in female animals may be due to the fact that female animals are kept longer for breeding and milk production purposes [26]. On other hand higher prevalence in female animals might be due to hormonal disturbances due to its use in milk production and breeding system which lowers the immune system of the animal.

In the present study highest prevalence of babesiosis was noted among old age (23.5\%) followed by adult (15\%) and young age cattle (13.2\%). This result was in line with the finding of Ayaz et al. [18] from Pakistan who reported high prevalence in old animals with $13.4 \%$ (61/452) followed by adult animals, $11.7 \%$ (48/409) while the lowest was found in young animals. However, the results of this paper disagree with Amorim et al. [27] who identified that calves were more susceptible to Babesia spp. when compared to adult cows. This variation can be due to the fact that young animals have less rate of infestation with tick as compared to old animals. On the other hand lower prevalence in young animals attributed due to restricted grazing 
Citation: Hamsho A, Tesfamarym G, Megersa G, Megersa M (2015) A Cross-Sectional Study of Bovine Babesiosis in Teltele District, Borena Zone, Southern Ethiopia. J Veterinar Sci Technol 6: 230. doi:10.4172/2157-7579.1000230

of young animals which likely to reduce their chance of contact the vectors of these diseases [26].

The prevalence of the disease based on the body condition of the animals was $5.47 \%, 15.6 \%, 35.9 \%$ for good, medium and poor scoring respectively with significant association $(P<0.05)$. This could be due to the fact that animals with poor body condition have lower immunity which encourages infection of animal by different organisms like Babesia. In addition, during this survey it was very common to see high burden of ectoparasite (ticks) in animal with poor body condition and this can increase rate of infection from babesia. Animals treated with babesiocide drugs have the prevalence of $10.87 \%$ and those untreated have $18.84 \%$. This finding showed that in area where regular treatments of animals with antiparasitic drugs (babesiocide drugs) were showed considerably low rate of infection.

The results of the present study showed slightly higher B. bovis (9.9\%) infection rate compared to B. bigemina (7\%) which coincides with the earlier prevalence $17 \%$ B. bovis and $16 \%$ B. bigemina from Malaysia as reported by Rahman et al. [19]. This is may be due to higher concentration of the former parasite in the capillary and veins than the latter parasite which evenly distributed in the whole blood vasculature. Previous studies have also indicated that cattle infected with $B$. bovis remain carriers for long periods, while those infected with $B$. bigemina remain carriers for only a few months [28].

In conclusion the present findings indicated that bovine babesiosis were highly prevalent in the study area. B. bovis and B. bigemina were identified as the species responsible for bovine babesiosis with greater prevalence of $B$. bovis. In order to alleviate the existing problem and to promote the status of the cattle dependent people living in these areas regular strategic prophylactic treatment and use of acaricides should be enhanced in order to the control of Babesia parasite. Further research should be conducted to elucidate the impacts and epidemiology of tick borne disease using immunological methods to implement better control measure against ticks and tick borne diseases of cattle and to validate the present study.

\section{Acknowledgements}

The authors highly acknowledge farmers of the study area their kind willingness and support during sample collection. Yabello regional laboratory staff members are also acknowledged for their technical support during sample processing in the lab.

\section{References}

1. Central Statistics Agency (CSA) (2009) Livestock Statistical Report Statistical Bulletin 302, Addis Ababa. pp. 23-29.

2. International Livestock Research Institute (ILRI) (2000) Livestock research for development, Addis Ababa, Ethiopia.

3. Ministry of Agricultural (MoA) (1997) Livestock development policies in Eastern and Southern Africa. Proceedings of a seminar organized by CTA, OAU/IBAR and the Ministry of Agriculture and Cooperatives, Swaziland.

4. Alekaw S (2000) Distribution of ticks and tick born diseases at Metekel ranch Ethiopia. J Ethiop Vet Assoc 4: 40-60.

5. Homer MJ, Aguilar-Delfin I, Telford SR, Krause PJ, Persing DHM (2000) Babesiosis. Clin Microbiol Rev 13: 451-469.

6. World Organisation for Animal Health (WOAH) (2012) Manual of Diagnostic Tests and Vaccines for Terrestrial Animals. OIE, Paris. pp. 42-47.
7. Hunfeld KP, Hildebrandt A Gray JS (2008) Babesiosis: Recent insights into an ancient disease. Int J Parasitol 38: 1219-1237.

8. Mekonnen S (1998) Ticks and tick born diseases and control strategies in Ethiopia Agricultural Research Council. Hoechst (Germany) OIE regional collaborating centre, pp. 441-446.

9. Sitotaw T, Regassa F, Zeru F, Kahsay AG (2014) Epidemiological significance of major hemoparasites of ruminants in and around Debre-Zeit, Central Ethiopia. J Parasitol Vector Biol 6: 16-22.

10. De-Lahunta A, Habel RE (1986) Teeth applied veterinary anatomy. W.B. Saunders Company. pp 4-6.

11. Nicholson MJ, Butterworth MH (1986) A guide to condition scoring of zebu cattle. International Livestock Centre for Africa, Addis Ababa. p. 29.

12. Thrusfield M (2005) Veterinary clinical pathology. Philadelphia and London. W.B. Saunders Company. pp. 451-479.

13. Urquhart GM, Armour J, Duncan JL, Dunn AM, Jennings FW (1996) Veterinary Parasitology $2^{\text {nd }}$ edition. Blackwell science, United Kingdom, pp. 307.

14. OIE (2010) Bovine Babesiosis, Terrestrial manual.

15. Soulsby (1982) Helminths, arthropods and protozoa of domesticated animals $7^{\text {th }}$ Edition. Baillere Tindall, London. pp. 456-475.

16. Ahmad N, Hashim H (2007) A comparative study on the incidence of ticks and ticks borne diseases on local and crossbred cattle in Malakand Agency. J Anim PI Sci 17: 56-58.

17. Farhan AA, Muhammad SK, Hafiz Jl, Ghulam MA, Ejaz A, et al. (2012) Prevalence of Anaplasma marginale, Babesia bigemina and Theileria annulata infections among cattle in Sargodha District, Pakistan. African J Agri Res 7 : 3302-3307.

18. Ayaz S, Shams S, Abdel-Reheem MAT, khan S, Ullah R (2013) Epidemiology and molecular detection of babesiosis in household Dairies in Districts Kohat and Karak, Khyber Pakhtunkhwa Pakistan. Life Science Journal, 10(10s).

19. Rahman WA, Lye YP, Chandrawathani P (2010) The seroprevalence of bovine babesiosis in Malaysian. Trop Biomed 27: 301-307.

20. Patcharathorn $S$, Nantawan $Y$, Nantiya $S$, Sinsamut $S$, Nongnuch $P$ et al. (2013) Prevalence and factors associated with Babesia spp. infections of cattle raised nearby forest in Salakpra Wildlife Sanctuary, Kanchanaburi province.

21. Cadder J, Reddy G, Chieves L, Courtney C, Little R, et al. (1996) Monitoring Babesia bovis infection in cattle by using PC based tests. J Clin Microbiol 34 2748-2755.

22. Gubbels JM, de vos AP, Van der Weide M, Viseras J, Schouls LM, et al. (1999) Simultaneous detection of bovine Theileria and Babesia species by reverse line blot hybridization. J Clin Microbiol 37: 1782-1789.

23. Nasir AA, Hashmi HA, Afzal M (2000) Prevalence of haemoparasites in exotic cattle. Int J Agri Biol 2(4): 402-403.

24. Angwech H, Kaddu JB, Nyeko JHP (2011) Tick-borne parasites of domestic ruminants in Gulu districts, Uganda: Prevalence varied with the intensity of management. Vet Res 4: 28-33.

25. Kocan KM, dela-Fuente J, Bouin EF, Coetzee JF, Ewing SA (2010) The natura history of Anaplasma marginale. Vet Parasitol 167: 95-107

26. Kamani J, Sannusi A, Egwu OK, Dogo GI, Tanko TJ, et al. (2010) Prevalence and significance of haemoparasitic infections of cattle in North-Central, Nigeria. Vet World 3: 445-448.

27. Amorim LS, Wenceslau AA, Carvalho FS, Carneiro PLS, Albuquerque GR (2014) Bovine babesiosis and anaplasmosis complex: diagnosis and evaluation of the risk factors from Bahia, Brazil. Braz J Vet Parasitol Jaboticabal 23: 328336

28. Bock R, Jackson L, de Vos A, Jorgensen W (2004) Babesiosis of cattle. Parasitol 129: 247-269. 